\title{
Mass spectral data for 64 eluted peptides and structural modeling define peptide binding preferences for class I alleles in two chicken MHC- $B$ haplotypes associated with opposite responses to Marek's disease
}

\author{
Mark A. Sherman, \\ Division of Information Sciences, City of Hope, Beckman Research Institute, Duarte, CA 91010, \\ USA \\ Ronald M. Goto, \\ Division of Molecular Biology, City of Hope, Beckman Research Institute, Duarte, CA 91010, USA \\ Roger E. Moore, \\ Division of Immunology, City of Hope, Beckman Research Institute, Duarte, CA 91010, USA \\ Henry D. Hunt, \\ Avian Disease and Oncology Laboratory, USDA Agricultural Research Service, East Lansing, MI \\ 48823, USA \\ Terry D. Lee, and \\ Division of Immunology, City of Hope, Beckman Research Institute, Duarte, CA 91010, USA \\ Marcia M. Miller \\ Division of Molecular Biology, City of Hope, Beckman Research Institute, Duarte, CA 91010, USA \\ Marcia M. Miller: mamiller@coh.org
}

\section{Abstract}

In the chicken, resistance to lymphomas that form following infection with oncogenic strains of Marek's herpesvirus is strongly linked to the major histocompatibility complex (MHC)- $B$ complex. MHC- $B 21$ haplotype is associated with lower tumor-related mortality compared to other haplotypes including MHC- $B 13$. The single, dominantly expressed class I gene (BF2) is postulated as responsible for the MHC- $B$ haplotype association. We used mass spectrometry to identify peptides and structural modeling to define the peptide binding preferences of $\mathrm{BF} 2 * 2101$ and $\mathrm{BF} 2 * 1301$ proteins. Endogenous peptides ( $8-12$ residues long) were eluted from affinitypurified $\mathrm{BF} 2 * 2101$ and $\mathrm{BF} 2 * 1301$ proteins obtained from transduced cDNA expressed in RP9 cells, hence expressed in the presence of heterologous TAP. Sequences of individual peptides were identified by mass spectrometry. BF2*2101 peptides appear to be tethered at the binding groove margins with longer peptides arching out but selected by preferred residues at positions $\mathrm{P} 3$, P5, and P8: X-X-[AVILFP]-X (1-5)-[AVLFWP]-X $_{(2-3)}$-[VILFM]. BF2*1301 peptides appear selected for residues at P2, P3, P5, and P8: X-[DE]-[AVILFW]- $\mathrm{X}_{(1-2)}-[\mathrm{DE}]-\mathrm{X}-\mathrm{X}-[\mathrm{ED}]-\mathrm{X}_{(0-4)}$. Some longer BF2*1301 peptides likely also arch out, but others are apparently accommodated by repositioning of Arg83 so that peptides extend beyond the last preferred residue at P8. Comparisons of these peptides with earlier peptides derived in the presence of homologous TAP transport revealed the same side chain preferences. Scanning of Marek's and other viral proteins with the BF2*2101 motif identified many matches, as did the control human leukocyte antigen 
A*0201 motif. The BF2*1301 motif is more restricting suggesting that this allele may confer a selective advantage only in infections with a subset of viral pathogens.

\section{Keywords}

Chicken MHC- $B$; MHC class I; Peptide binding motif; $B F 2 * 2101 ; B F 2 * 1301$

\section{Introduction}

The domesticated chicken provides one of the best examples of linkage between major histocompatibility complex (MHC) genetics and resistance to infectious disease. An exceptionally strong relationship exists between particular MHC- $B$ haplotypes and the growth of tumors following infection with the oncogenic Marek's herpesvirus. Having at least one MHC haplotype conferring resistance, notably B 21, allows birds infected with virulent strains of Marek's herpesvirus to remain mostly tumor free in typical challenge trials (Briles et al. 1977). In contrast, many other haplotypes generally contribute more moderate resistance (B2) or little to genetic resistance (B13, B15, and B19) to Marek's disease (MD; Briles et al. 1977; Bacon et al. 2001). Rapidly growing T-cell lymphomas follow infection of birds carrying susceptible $B$ haplotypes. $B$ haplotypes also influence the relative efficacy of the vaccines used to protect commercially grown chickens from MD (Bacon and Witter 1992, 1993, 1994a, b, 1995; Lee et al. 2004). The genetic basis of the MHC-linked disease resistance and enhanced efficacy of vaccination remains unresolved. There are a number of polymorphic loci within the $B$ region that could contribute to MD resistance (Briles et al. 1983; Plachy et al. 1984; Shiina et al. 2007). It has been proposed that differential action of alleles at the single dominantly expressed classical class I gene locus (BF2) and perhaps coevolution of nearby supporting loci, especially TAP genes, may be responsible for the observed differences among $B$ haplotypes in susceptibility to disease (Kaufman et al. 1995, $1999 \mathrm{a}, \mathrm{b}$ ). The nature of peptides bound by different BF2 alleles is of interest for understanding how possessing $B 21$ haplotype results in protection against MD tumors and how different haplotypes influence immune responses to MD vaccines.

Sequence comparisons, structural modeling, and now the first BF2 structure, published as the final version of this manuscript was being completed following initial review, demonstrate that MHC class I molecules in chicken are highly similar to their mammalian counterparts (Guillemot et al. 1988; Kaufman and Salomonsen 1993; Wallny et al. 2006; Koch et al. 2007). Peptide is usually bound in an extended confirmation in the antigen binding groove via interactions similar to those now well understood for many class I molecules through detailed analyses of many class I crystal structures (see reviews Madden 1995; Maenaka and Jones 1999; Pamer and Cresswell 1998; Rudolph et al. 2006). Peptides are tethered through interactions between side chains in the binding groove and the backbone atoms at each end of the peptide. Human leukocyte antigen (HLA) allelic preferences for different peptide sequences result from pockets along the binding groove selectively accommodating particular peptide side chains. Different class I allotypes can be distinguished, in part, by different residues lining the pockets with different types of peptides being preferentially accommodated in different allotypes.

We chose to define the peptide binding preferences for the BF2 proteins encoded in two $B$ haplotypes ( $B 21$ and B13) associated with opposite outcomes in MD challenge trials using mass spectrometry to identify the sequences of individual peptides. FLAG-epitope-tagged MHC I full-length cDNA clones for the $B F 2 * 2101$ and $B F 2 * 1301$ alleles were expressed in RP9 cells, a chicken B-lymphoblastoid cell line that can be cultured easily to provide large numbers of cells. In this system, $B 2$ and $B 15$ TAP alleles are available for transport of 
peptide into the endoplasmic reticulum (ER). FLAG-tagged molecules were purified by affinity chromatography and peptides eluted for analysis by high-performance liquid chromatography (HPLC)-tandem mass spectrometry (LC-MS-MS) following an established protocol. The sequences of the eluted peptides were analyzed and structural models developed to define binding preferences for the two alleles using the peptides loaded in this heterologous TAP expression system. To gain insight into the relative potential of alleles to support immune responses to diverse pathogens, the protein sequences of a variety of avian pathogens were scanned with the peptide binding motifs derived in this study for $\mathrm{BF} 2 * 2101$ and $\mathrm{BF} 2 * 1301$.

\section{Materials and methods}

\section{Cell lines}

FLAG-epitope-tagged $B F 2 * B 1301$ and $B F 2 * 2101$ cDNA clones were expressed in RP9 (LSCC-RP9) cells, a B-lymphoblastoid cell line derived from a tumor induced in a $15 \mathrm{I}_{5} \times 7_{2}$ chicken by Rous-associated virus-2 (RAV-2), a subgroup B avian leukosis virus (Okazaki et al. 1980). RP9 cells are heterozygous at MHC- $B$ bearing $B 2$ and $B 15$ haplotypes.

\section{Cloning and expression of BF2 cDNA}

$B F 2 * 1301$ (AF013494) and BF2*2101 (AF013493) were cloned from cDNA using primers specific for the $B F 2$ locus from Avian Disease and Oncology Laboratory congenic lines 15.P-13 and 15.N-21 (Hunt et al. 1994; Hunt and Fulton 1998). FLAG epitope (amino acid sequence DYKDDDDK) coding sequences were introduced upstream of exon 2 in each clone using splicing by overlapping extension (Ho et al. 1989). Following verification of the sequences, the constructs were introduced into the avian retroviral vector RCASBP(A) (Petropoulos and Hughes 1991) and transfected into DF1 cells. Transfected DF1 cell culture supernatants were used to infect the RP9 cells and these were in turn selected by flow cytometry for uniform surface expression of the FLAG epitope as previously described (Fulton et al. 1995).

\section{Isolation of epitope-tagged MHC class I molecules and elution of endogenous peptide}

FLAG-epitope-tagged MHC class I molecules were isolated from 1.0 $\times 10^{10}$ transduced RP9 cells following an established procedure for immunoaffinity purification (Cox et al. 1994). Briefly, cells were collected in batches of $\sim 10^{9}$ cells, washed in phosphate-buffered saline, pelleted, and stored at $-80^{\circ} \mathrm{C}$. Accumulated batches were thawed in the presence of freshly made lysis buffer $(150 \mathrm{mM} \mathrm{NaCl}, 20 \mathrm{mM}$ Tris $\mathrm{HCl}, \mathrm{pH}$ 8.0, $1 \%$ CHAPS, $100 \mu \mathrm{M}$ iodoacetamide, $5 \mu \mathrm{g} / \mathrm{ml}$ aprotinin, $10 \mu \mathrm{g} / \mathrm{ml}$ leupeptin, $10 \mu \mathrm{g} / \mathrm{ml}$ pepstatin A, $5 \mathrm{mM}$ ethylene diamine tetraacetic acid, $0.04 \%$ sodium azide, and $1 \mathrm{mM}$ phenylmethylsulfonyl fluoride) and pooled. The mixture was stirred gently for $1 \mathrm{~h}$ at $4^{\circ} \mathrm{C}$ and centrifuged for $1 \mathrm{~h}$ at $100,000 \times g$. Supernatant was collected and filtered through a $0.2-\mu \mathrm{m}$ Acrodisc syringe filter (Pall) and loaded on a M2 Agarose Affinity Gel (Sigma) column. The column was washed with two column volumes of lysis buffer followed by 20-column volumes each of $20 \mathrm{mM}$ Tris, $\mathrm{pH} 8.0,150 \mathrm{mM} \mathrm{NaCl} ; 20 \mathrm{mM}$ Tris, $\mathrm{pH} 8.0,1.0 \mathrm{M} \mathrm{NaCl}$; and $20 \mathrm{mM}$ Tris, $\mathrm{pH}$ 8.0. Class I molecules were eluted with $0.2 \mathrm{~N}$ acetic acid. Eluted samples were brought to a final concentration of $10 \%$ acetic acid, heated in boiling water for $5 \mathrm{~min}$, and chilled on ice. Peptides were separated from larger molecules by ultrafiltration using Amicon Ultrafree-CL PLCC Centrifugal Filter Units with 5-kDa cutoff. The effluent was concentrated to a volume of approximately $100 \mu \mathrm{l}$ and frozen until further analysis. Peptides were fractionated on a $2.1 \times 40 \mathrm{~mm} \mathrm{C} 18$ reverse-phase support HPLC using a water-acetonitrile gradient and $0.1 \%$ trifluoroacetic acid as the ion-pairing agent. 


\section{Mass spectrometry}

Peptide fractions were analyzed using a Finnigan LCQ Classic mass spectrometer. LC-MSMS analyses were performed using C18 capillary columns $(150 \mu \mathrm{m} \times 50 \mathrm{~mm}$ or $75 \mu \mathrm{m} \times 150$ $\mathrm{mm})$. GenBank sequences were searched with SEQUEST. Matches were manually validated.

\section{Molecular modeling of peptide-BF2 complexes}

Models of peptides bound to BF2*1301 and BF2*2101 (Fig. 1) were built using a previously published protocol (Tong et al. 2004). For modeling BF2*1301 bound to NDIEEHLE, crystal structures of three MHC class I molecules bound to octameric peptides having secondary anchor residues at positions P2, P3, P5, and P8 were selected as modeling templates (PDB files 1UXS, 1E27, 1A9E). The program MODELLER 9.0 (Sali and Blundell 1993) running within Discovery Studio 2.0 (Accelrys, San Diego, CA, USA) was used to generate 200 initial models of medium refinement (fast molecular dynamics annealing). Of the resulting models, the ten having the lowest total energy were used as templates for generating 100 additional models of high refinement (thorough molecular dynamics annealing). The model whose peptide had the lowest energy was selected as the final model and used as a template for modeling both LDVEDVKF and LDIVKELKE bound to BF2*1301. Models of NDIEEHLEE, IDWFDGKEF, and IDWFDGKEFNGN bound to $\mathrm{BF} 2 * 1301$ were likewise created using NDIEEHLE bound to $\mathrm{BF} 2 * 1301$ as a template. However, residues following the conserved $\mathrm{E}$ at position 8 (italicized) were modeled as C-terminal overhangs that protruded from the groove. Models of BF2*2101 bound to three peptides (nonamer, decamer, and dodeca-mer) were built using BF2*1301 bound to nonoverhang peptides (NDIEEHLE, LDVEDVKF, and LDIVKELKE) as templates.

\section{Motif definition}

Initially, the SEQUEST matches for each sample were manually aligned and sorted by size. Alignments were refined following molecular modeling. The numbers of each amino acid at each position were tabulated; those in each class summed and percent noted in Figs. 2 and 3. Positions where a single class of amino acids was found in more than $70 \%$ of the peptide sequences were assigned and used in motif scanning. A motif for HLA A*0201 was derived with the same approach using the endogenous peptides available in the SYFPEITHI database (http://www. syfpeithi.de/).

\section{Motif scanning}

Peptide motifs for BF2*2101, BF2*1301, and HLA A*0201 were used to scan the protein sequences encoded in the genomes of various avian viral pathogens available at the National Center for Biotechnology Information (http://www.ncbi.nlm.nih.gov/genomes/VIRUSES/viruses.html) using the Los Alamos National Lab HIV HLA Anchor Residue Motifs (Motif Scan) website (http://www.hiv.lanl.gov/content/immunology/motif_scan/motif_scan). Since the motifs for each allele encompassed peptides that differed in length, the motif of length variants were scanned separately and then the totals summed.

\section{Results}

\section{Eluted peptides and molecular modeling}

RP9 cells expressing FLAG-epitope-tagged BF2*2101 and BF2*1301 in the context of heterologous TAP alleles (see discussion below) were grown in large numbers. MHC I molecules were isolated and peptides eluted. The eluted peptides were subjected to LC-MS- 
MS following the procedure described above. Overall, 64 peptides were identified. Thirtyfour were from $\mathrm{BF} 2 * 2101$ and 30 from $\mathrm{BF} 2 * 1301$. These varied in length from eight to 12 residues with most B21 peptides (21/34) containing ten amino acids and most B13 peptides (19/30) containing nine. Because of variation in length, it was difficult to derive motifs that described all peptides for each allele using simple alignments. Hence, we generated models for the $\mathrm{BF} 2 * 2101$ and $\mathrm{BF} 2 * 1301$ binding grooves based on structures of similar MHC class I molecules. The models are consistent with highly conserved residues at the margins of the $\mathrm{BF} 2 * 2101$ and $\mathrm{BF} 2 * 1301$ binding grooves tethering peptides through hydrogen bonding networks between atoms in the peptide backbone and conserved residues lining the margins of the binding groove (Fig. 1a). As noted previously (Kaufman et al. 1994), an arginine (Arg83) in chicken class I and other nonmammalian vertebrates replaces a tyrosine (Tyr84) in the equivalent position in mammalian classical MHC 1 molecules. Residues that likely interact with peptide point into the groove and are illustrated in the models in Figs. 1b,c. Some of these differ between $\mathrm{BF} 2 * 2101$ and $\mathrm{BF} 2 * 1301$ defining peptide binding preferences.

One model for peptide bound in BF2*2101 was built using the decamer peptide SELKDFFQKL (peptide 9 in Fig. 2). The side chain interactions which are likely the key in determining preferential accommodation of this peptide in the binding groove are illustrated in a side view (Fig. 1d). R9 interacting with glutamic acid at peptide position 2 (P2), Y156 and L153 with the leucine at P3, H111 with phenylalanine at P5, and L80 with the carboxyterminal leucine at $\mathrm{P} 8$ are the residues critical in the selection of this peptide.

NDIEEHLE bound to the BF2*1301 model illustrates the residues likely contributing to the accommodation of octameric peptides in this allele (Fig. 1e; peptide 1 in Fig. 3 where the notation $\mathrm{P}^{\prime}$ is used to align longer peptides). Three arginine residues in the BF2*1301 model are available for interacting with the three acidic residues commonly found within the BF2*1301 peptides. This is consistent with the published model for BF2*0401, an allele having the same $a 1$ and $a 2$ sequence (Wallny et al. 2006). R9 interacts with aspartic acid at peptide P2, R111 with glutamic acid at P5, and R80 with glutamic acid at P8. The residues Y156 and W153 interacting with isoleucine at P3 in this model support the observed hydrophobic nature of the $\mathrm{P} 3$ residue in $\mathrm{BF} 2 * 1301$ peptides listed in Fig. 3.

Longer peptides were also modeled in the binding grooves of both allotypes. In BF $2 * 2101$, the ends of all longer peptides likely remain buried in the groove resulting in these peptides arching upward between P3 and P5 (Fig. 1f) quite similar to longer peptides found in mammalian MHC I structures (Fremont et al. 1992; Guo et al. 1992; Matsumura et al. 1992; Speir et al. 2001; Tynan et al. 2005). Three of the longer BF2*1301 peptides (peptides 8-10 in Fig. 3) most likely arch out of the groove as well. A model for peptide 8 (gray peptide in Fig. 1g), the nonameric peptide LDIVKELKE, is provided as an example. It bulges out of the groove in order for the interactions of acidic residues at P2, P5, and P8 to be accommodated in the pockets defined by R9, R111, and R80 and P3 to be accommodated in the hydrophobic pocket defined by W153. Modeling for the remainder of the longer BF2*1301 peptides (peptides 11-30 in Fig. 3) suggests that acidic side chains are accommodated at positions $\mathrm{P} 2, \mathrm{P} 5$, and $\mathrm{P} 8$ and the hydrophobic side chain at $\mathrm{P} 3$ without bulging. It is likely that these peptides extend out along the axis of the groove as a result of the conformational flexibility of the Arg83 side chain. The model suggests that Arg80, a buried residue which defines the charged nature of the pocket for P8 in BF2*1301, and Arg83 are physically close. Because of charge clash between these two residues, Arg83 likely repositions itself more distant from $\operatorname{Arg} 80$ (compared to its position in BF2*2101 with respect to Leu80) but still retains the ability to form a salt bridge with the carboxy-terminus of bound peptides. Modeling of peptides having additional residues beyond $\mathrm{E}$ or $\mathrm{D}$ at P8 
indicates that the side chain of R83 is sufficiently flexible to accommodate at least four added residues, as illustrated in Fig. 1i compared to Fig. $1 \mathrm{~h}$.

\section{Peptide binding motif for BF2*2101}

With insight into which residues likely result in selection of peptides for binding to $\mathrm{BF} 2 * 2101$, we could rationally align the $34 \mathrm{BF} 2 * 2101$ peptides of varying lengths (Fig. 2). Since modeling suggests that the ends of all peptides are likely bound at the same positions at the margins of the groove and longer peptides arch out of the groove, gaps were introduced to allow alignment of anchor residues at P3, P5, and P8. The P3', P3", P3"', and $\mathrm{P}^{\prime \prime \prime \prime \prime}$ positions designate $\mathrm{BF} 2 * 2101$ peptide residues that bulge out of the groove between $\mathrm{P} 3$ and P5. P5' is used to describe the sequences of two peptides that have an extra, bulging residue between $\mathrm{P} 5$ and $\mathrm{P} 8$. The alignment confirms the importance of hydrophobic residues at P3, P5, and P8 as suggested by the BF2*2101 model in Fig. 1d. Hydrophobic residues dominate at these positions: $76 \%$ at $\mathrm{P} 3,74 \%$ at $\mathrm{P} 5$, and $97 \%$ at P8 (Fig. 2). If polar tyrosine is included because of its hydrophobic properties along with the hydrophobic amino acids, then the preference for amino acids with hydrophobic properties at P3, P5, and P8 climbs to $82 \%, 97 \%$, and $100 \%$, respectively. Hydrophobic residues are also frequently found at P4 $(47 \%)$. There is an apparent preference for basic residues at P7 (47\%) and acidic residues at P2 (41\%) and P6 (41\%) with asparagine and glutamine also frequent at the latter two positions. The finding of two octameric peptides suggests that peptides as short as eight residues can bind in the $\mathrm{BF} 2 * 2101$ groove; however, we cannot exclude that post-isolation proteolysis resulted in inclusion of these peptides. All $34 \mathrm{BF} 2 * 2101$ peptides are distinct except for two pairs. In each of these pairs, one member is two residues shorter than the other at the amino-terminal end. One pair is the octamer LKDFFQKL and the decamer SELKDFFQKL. The other is the decamer PEALDFLDKL and the dodecamer VSPEALDFLDKL. In both instances, the longer peptides likely arch out while the shorter peptides likely span the binding groove and are tethered by the typical main chain interactions at the peptide ends. The decamer PEALDFLDKL and the longer VSPEALDFLDKL peptide both have hydrophobic residues at P3, P5, and P8. The distribution of amino acid residues across the 34 peptides aligned in Fig. 2 shows that the $\mathrm{BF} 2 * 2101$ allele, like other MHC class I molecules, exhibits a preference for a subset of peptides with similar properties. The $\mathrm{BF} 2 * 2101$ peptide alignment defines the motif: $\mathrm{X}-\mathrm{X}$ [AVILFP]-X $\mathrm{X}_{(1-5)^{-}}[\mathrm{AVLFWP}]-\mathrm{X}_{(2-3)^{-}}$[VILFM].

\section{Peptide binding motif for BF2*1301}

The alignment of the $30 \mathrm{BF} 2 * 1301$ peptides in Fig. 3 from the N-terminus is suggested by molecular modeling. The alignment confirms a preference at $\mathrm{P} 2$ for acidic residues where glutamic or aspartic acids are found in 28 of the 30 amino acids. Position P3 is occupied nearly exclusively (93\%) by hydrophobic residues (A, V, I, L, F, W). Introduction of the P3' gap suggested by modeling for three peptides that likely bulge from the groove solidifies the importance of aspartic and glutamic acid residues at P5 and P8, 97\% and 80\%, respectively. A weaker preference of hydrophobic residues at P1 (57\%), P4 (60\%), and P6 (57\%) is also apparent. The alignment highlights the presence of additional residues beyond $\mathrm{P} 8$ in more than half the BF2*1301 peptides. We believe that these are most likely accommodated as noted above by repositioning of Arg83. Two pairs of overlapping peptides (peptides 1 and 11 and peptides 29 and 30) provide further support for the likelihood that peptides are accommodated by carboxy-terminal extensions. The peptides listed in Fig. 3 define a $\mathrm{BF} 2 * 1301$ motif with defining residues at four positions: $\mathrm{X}$-[DE]-[AVILFW]-X $\mathrm{X}_{(1-2)}$-[DE]$\mathrm{X}-\mathrm{X}-[\mathrm{DE}]-\mathrm{X}_{(0-4)}$. 


\section{Motifs in the proteins of avian viral pathogens}

To look for evidence of differences between the $\mathrm{BF} 2 * 2101$ and $\mathrm{BF} 2 * 1301$ alleles in the capacity to bind peptides from the virulent Gallid herpesvirus 2 (GaHV-2) and other avian viral pathogens for which genome sequences are available, scans were made with each of the above motifs using the Motif Scan algorithm (http://www.hiv.lanl.gov/content/immunology/motif_scan/motif_scan). Large differences in the number of matching GaHV-2 peptides are evident in scans of the full array of GaHV-2 peptides with the BF2*2101 and BF2*1301 motifs (Table 1 ). Nearly 400 times more matches are found with the $\mathrm{BF} 2 * 2101$ motif than with that of $\mathrm{BF} 2 * 1301$ (15,652 compared to 42). When Meq, the Marek's virus oncogene encoded transcription factor that is specific to tumor causing Marek's herpesvirus strains, is considered separately, 49 peptide sequences are identified as matching the $\mathrm{BF} 2 * 2101$ motif while no matches are found with the $\mathrm{BF} 2 * 1301$ motif (Table 1 ). Even though only a fraction of the array of peptides identified with Motif Scanner are likely to bind when tested in vivo or likely would be predicted with more advanced software (Lin et al. 2008), the comparison suggests that possessing the $\mathrm{BF} 2 * 2101$ allele in the face of infection with GaHV-2 might be advantageous compared to BF2*1301 allele, as also noted by Koch et al. (2007).

To try to understand the apparent broad specificity of the BF2*2101 allele, two further comparisons were made. We first compared BF2*2101 to the human HLA A*0201 allele as a means of gaining insight into how specialized it might be. Peptides bound by HLA $\mathrm{A}^{*} 0201$, an allele commonly found in many human populations, are well studied (Falk et al. 1991; Rotzschke et al. 1992; Sudo et al. 1995) and nearly 300 sequences for HLA A*0201 endogenous peptides are available in the SYFPEITHI database (http://www.syfpeithi.de/). Like BF2*2101, the HLA A*0201 allele binds peptides varying in length (from eight to at least 14 amino acids). HLA $A * 0201$ has anchor residues at positions $\mathrm{P} 2$ and $\mathrm{P} 9$. To be able to make a comparison, we generated a motif for HLA A*0201 that accommodates length variants using the same procedure described above for $\mathrm{BF} 2 * 2101$ and $\mathrm{BF} 2 * 1301$. All of the endogenous peptide sequences available in the SYFPEITHI database could then be aligned with the anchors at positions $\mathrm{P} 2$ and $\mathrm{P} 9$. This revealed that $\mathrm{P} 2$ and $\mathrm{P} 9$ are occupied almost exclusively by hydrophobic residues (93\% at both positions with some hydrophobic residues found more frequently than others). Using this motif that identified all the hydrophobic residues found at $\mathrm{P} 2$ and $\mathrm{P} 9$ and accommodated length variants,

X[AVILMP]X $X_{(6-12)}$ [AVILFMP], we scanned GaHV-2 proteins for matches. A large number of peptides matches $(46,804)$ were found within the GaHV-2 proteins (Table 1). The number of matches actually exceed those found with the $\mathrm{BF} 2 * 2101$ motif both overall and within the oncoprotein meq. From this comparison, it can be concluded that while $\mathrm{BF} 2 * 21$ is predicted to bind many GaHV-2 peptides, it is not an extraordinary MHC class I allele in this capacity.

To further evaluate the $\mathrm{BF} 2 * 2101$ motif, we expanded motif scanning to include the genome sequences for additional viral pathogens (Table 2). Many BF2*2101 matches are present in the proteins of every viral genome. We have used a ratio of peptide matches per 100 amino acids as a means for comparing the matches found in the proteins of different viruses. For the viruses listed in Table 2, the ratios for $\mathrm{BF} 2 * 2101$ peptide matches range from 13 to 50 peptides per 100 amino acids indicating that every virus regardless of genome size has many peptides that fit the $\mathrm{BF} 2 * 2101$ motif. This evaluation indicates that other avian viral pathogens are similar to GaHV-2 in having many peptides matching the BF $2 * 2101$ motif.

Scans with the $\mathrm{BF} 2 * 1301$ motif provide a contrasting picture. Just as there are far fewer $\mathrm{BF} 2 * 1301$ motif matches with the GaHV-2 proteins compared to the $\mathrm{BF} 2 * 2101$ motif, there are also far fewer matches in $\mathrm{BF} 2 * 1301$ motif scans of the proteins of other viral pathogens. Among the 34 viral genomes in Table 2, over one quarter of them (9/34) yield no matches. When matches do occur, they are nearly 200 times less frequent (average 0.17/100 amino 
acids) than the $\mathrm{BF} 2 * 2101$ motif matches. The $\mathrm{BF} 2 * 1301$ motif requiring four anchor residue positions, three of which are acidic residues, is rarely found in the proteins of avian viral pathogens. It could be that since only a portion of the viral protein sequences contain matches that the $\mathrm{BF} 2 * 1301$ allele may confer a selective advantage only when challenged by a subset of pathogens. In contrast, the $\mathrm{BF} 2 * 2101$ motif is commonly found in a variety of viral pathogens suggesting that the $\mathrm{BF} 2 * 2101$ allele may be retained in chicken populations as a result of its general utility in presenting peptide antigens from various sources.

\section{Discussion}

It is necessary to consider whether expressing $B F 2 * 1301$ and $B F 2 * 2101$ alleles with heterologous $T A P$ has influenced the type of peptides we obtained. In rat, peptide transport is affected by TAP and MHC class I pairing (Powis et al. 1996; Deverson et al. 1998; Joly et al. 1998). Single-nucleotide polymorphism and SSCP data provide evidence that chicken TAP1 and TAP2 are polymorphic across haplotypes (Wong et al. 2004; Walker et al. 2005). Kaufman and colleagues (Kaufman 1999; Kaufman et al. 1999a; Walker et al. 2005) have suggested that since chicken $T A P$ and $B F 2$ are physically adjacent, alleles at these loci might have evolved to cooperate in peptide selection and presentation. Currently, the only supporting evidence is a correlative and more studies are needed. There are positively charged residues in the B4-encoded TAP that correlate with the positively charged BF2*0401 binding pocket and with the preference for negatively charged peptides by this allele.

There are several observations to consider in evaluating whether the expression of $B F 2$ in the presence of heterologous $T A P$ has in any way affected the motif derived in this study. (1) The products of both transduced $B F 2$ alleles are well expressed on the surface of RP9 cells. RP9 cells expressing BF2*2101 have 110 mean channels of fluorescence (mcf) in flow cytometry assays when labeled with anti-beta 2 -microglobulin. RP9 cells expressing $\mathrm{BF} 2 * 1301$ cells are twice as bright (217 mcf; M. Miller and R. Goto, unpublished data). Both levels are within the typical range for these assays. The relatively lower expression of the transduced $\mathrm{BF} 2 * 2101$ gene may be a reflection of some, as yet unidentified, property of this allele that generally results in lower expression of $\mathrm{BF} 2 * 2101$ at the cell surface, as has been seen in other studies (Kaufman et al. 1995; Juul-Madsen et al. 2000). If the TAP alleles within RP9 cells transported only entirely unsuitable peptides into the ER, then poor surface expression of the transduced BF2 alleles would have occurred. (2) The same transduced RP9 cell lines expressing BF $2 * 2101$ and $\mathrm{BF} 2 * 1301 \mathrm{cDNA}$ from the avian leukosis virus RCASBP(A) vector were used in an earlier study that showed specific recognition by cytotoxic T cells obtained from chickens carrying the BF21 and B13 haplotypes that had been challenged with RAV-1 SRA (a subgroup A leukosis virus; Thacker et al. 1995). This shows that heterologous pairing of TAP and BF2 did not abrogate T-cell recognition of the $\mathrm{BF} 2 * 2101$ and $\mathrm{BF} 2 * 1301$ alleles expressed in the RP9 cell system even though we cannot exclude the possibility that the array of viral peptides on the transduced RP9 cell might differ in relative abundance from those found in the infected birds for a number of reasons including skewing by heterologous TAP loading. (3) The motifs revealed through expression with heterologous TAP are consistent with current published data obtained when the alleles are expressed in the context of their natural TAP homologs, presented by the $\mathrm{BF} 2 * 0401$ allele even though the current study with more data has revealed evidence of selection at an additional position. All three of the individual BF $2 * 0401$ peptide sequences (all octamers) previously published (Wallny et al. 2006) fit the BF2*1301 motif derived using expression with heterologous TAP (Table 3). Indeed, one of the peptides, LDVEDVKF, is also found among the 30 peptides eluted from BF2*1301 (Fig. 3). Since this peptide ends with phenylalanine, it appear that peptides with C-terminal hydrophobic residues gain access to the ER when transported by $B 4 T A P$ molecules just as they do with 
the heterologous TAP molecules available in RP9 cells. Another BF $2 * 0401$ peptideIDWFDGKE-overlaps BF2*1301 peptide 29 (IDWFDGKEFNGN) and peptide 30 (IDWFDGKEF) and provides further indication that peptides transported by the TAP molecules in RP9 cells are much the same as their naturally delivered counterparts (Fig. 3). A significant difference in the current analysis is in peptide length. Additional studies are needed to determine whether similar length variants occur when BF2*1301-BF2*0401 alleles are expressed in the context of their natural TAP alleles.

The detailed motifs defined here are more detailed than those typically reported because they are derived from large numbers of individual peptide sequences (Figs. 2 and 3). Each amino acid found within each dominant class is included even if found only once in the study since this analysis (where amino acids are grouped based on similar physical properties) suggests that similar physical properties are predictive of peptide selection. Presumably, other peptides with these residues at this position could also bind within the groove. This way of describing the positions that affect peptide selection primarily affects the tabulation of hydrophobic residues since eight amino acids are in this class. Hydrophobic interactions are common to peptide binding in the antigen binding groove and tabulating findings in this way helps to reveal their interchangeability. Pooled sequencing, upon which the concept of anchor residues is built, reveals only more frequently found residues. The resolution afforded by sequencing individual peptides was evident early in the application of mass spectrometry to the sequencing of eluted peptide. Hunt et al. (1992) found the Cterminal residue of HLA-A2.1 peptides to be leucine-isoleucine or alanine more often than valine, the single residue that had been categorized as a "dominant" anchor based on prior pooled sequencing. With the detailed motifs generated in this study, we anticipated that large numbers of matching peptides would be found in nearly all sets of proteins interrogated with all motifs. This was true in scans with the motifs for BF $2 * 2101$ and HLA $\mathrm{A}^{*} 0201$ (Tables 1 and 2), but the overall paucity of matches in scans with the BF2*1301 motif was not anticipated (Table 2) even though we were aware of how few peptide matches were reported for Rous sarcoma virus proteins (Kaufman et al. 1995; Wallny et al. 2006).

The $\mathrm{BF} 2 * 2101$ model generated in this study is largely validated by the recently published crystal structure for BF $2 * 2101$ (Koch et al. 2007). From our model, we expected P8 to be hydrophobic. The crystal structure confirms this along with the conserved residues that contribute main chain interactions for binding the peptide amino-terminus. There is agreement between the B21 structure and our model where we anticipated that the side chains of residues P2, P3, P5, P6, and P8 would reside within the binding groove. We detected a preference for glutamic and aspartic acid residues at P2 and P6 (PC-2; see Fig. 2) but we were unable to predict their role in peptide binding reported by Koch et al. (2007). Although their role in selectivity could not be anticipated in the crystal structure studies, a preference for residues with hydropho-bic properties at P3 and P5 (PC-3 in Koch et al.) is readily apparent when the sequences of the peptides eluted from $\mathrm{BF} 2 * \mathrm{~B} 2101$ are aligned (Fig. 2). The BF2*2101 motif derived here encompasses the two peptides used by Koch and colleagues in growing BF $2 * 2101$ crystals (Table 3 ). So the findings of the two studies are generally consistent. This study, because of the number of identified peptides, provides insight into which residues participate in peptide selection. In contrast to the prediction by Koch and colleagues, these peptides include two octameric peptides for BF $2 * 2101$. The presence of these two octameric peptides indicates that perhaps not all peptides bound by BF2*2101 adopt the helical conformation revealed by the crystal structure for the deca- and undeca-peptides, although their origin in postisolation proteolysis has not been ruled out.

Now that a BF2*2101 motif is known, it is clear why sequences of individual peptides were needed to reveal it. The chain length variation inherent in peptides bound by BF2*2101 peptides (visualized in Fig. 2) would make it difficult to detect patterns among residues in 
pooled peptide sequence data. Even with individual sequences available for $34 \mathrm{BF} 2 * 2101$ peptides, we found it necessary to render models for peptide binding in order to expose the anchor residues consistent with binding of peptides of varied length. Virtually all proteins produced by avian viral pathogens contain sequences fitting the BF2*2101 motif. Perhaps $B F 2 * 2101$ has been selected in natural populations for its general utility and remains in commercial breeding populations because it is advantageous for presenting a variety of antigens.

The BF $2 * 1301$ peptide binding motif revealed unexpected, interesting properties that may reflect the means by which this BF2 allele is retained in chicken populations. The BF2*1301 peptide binding motif contrasts with most MHC class I motifs. The constraint of four dominant anchor residues and that three of these must be acidic residues strongly limits the number of matches found in motif scans with the BF $2 * 1301$ motif. For some viruses with small genomes, peptides with the BF $2 * 1301$ motif are entirely missing within the proteins they encode. For others, only one or two proteins contain sequence matching this motif. The $\mathrm{BF} 2 * 1301$ matches found within the proteins of small viruses are most often within the sequence of a polymerase, primase, endonuclease, terminase, or other molecules that interact directly with nucleic acids. For example, the three BF $2 * 1301$ matches found in infectious bursal disease (IBDV) proteins are all within polymerases. Similarly, a majority of the matches with the eight avian influenza (AI) viral segments are within polymerase sequences. Also, within the sequence of larger viruses, where there are multiple matches in different proteins, there is typically at least one match within a polymerase or another protein interacting with nucleic acid. The selective nature of these matches with a class of proteins suggests that the $B F{ }^{*} 1301$ allele may have evolved in chicken populations because of an advantage in guiding immune responses in the face of challenges by particular small viral pathogens. The likelihood that the $B F 2 * 1301$ will contribute to immune responses to a variety of these viruses perhaps with similar protein sequences may have lead to its selection, even though the narrow specificity contrasts with the broad specificity of the $\mathrm{BF} 2 * 2101$ motif. The capacity to elicit immune responses to viruses such as those like AI and IBDV that cause death at an early age might be sufficient for the rise of B13 haplotype in the progenitors of contemporary chickens.

A previously unappreciated feature of the $\mathrm{BF} 2 * 1301$ allele is its capacity to bind longer peptides likely through repositioning of the Arg83 residue at the right margin of the peptide binding groove. This could be advantageous allowing a more extensive presentation of antigens by the $\mathrm{BF} 2 * 1301$ allele that is otherwise restricted by the four anchor residues it requires. Apparently, similar extensions do not occur in mammalian class I molecules where tyrosine, a residue without equivalent flexibility, is found in the corresponding position. The only mammalian structure showing an overhang has a single glycine extending beyond the groove (Collins et al. 1994). It may be that other nonmammalian MHC class I molecules, which have an arginine at position 83, also accommodate the extension of longer peptides along the axis of the binding groove. This could be a means for accommodating peptides derived from more primitive proteolytic pathways and/or underlie a distinctive means of presenting antigen to $\mathrm{T}$ cells found in nonmammalian vertebrates.

In summary, this study extends other recent investigations of chicken MHC-B class I and class II molecules (Cumberbatch et al. 2006; Haeri et al. 2005; Kaufman et al. 1995; Wallny et al. 2006; Koch et al. 2007) and will support further comparative studies on the effect of $B$ haplotype on vaccinal immunity (Bacon and Witter 1992, 1993, 1994a, b, 1995; Lee et al. 2004). Emerging is the understanding that some BF2 allotypes are likely similar to their mammalian counterparts in having the potential to bind a wide variety of peptides conforming to accommodating motifs. However, it is likely that other alleles, currently represented by $\mathrm{BF} 2 * 1301-\mathrm{BF} 2 * 0401$, display a contrasting stringent requirement for 
sequences. Surely BF2 molecules contribute directly and indirectly to the effectiveness of disease responses, but it is still not clear whether a single particular antigen presenting locus contributes specifically in genetic resistance to a particular pathogen, as is well described for Marek's disease. The apparent stringent requirement of the BF2*1301 allele for particular peptides raises the question of whether animals homozygous for this allele thrive under challenge by viral pathogens lacking peptides that can be presented by BF2*1301. If they do, this could be evidence of the redundant nature of immune defense and the importance of other chicken genes in responses to viral pathogens. Tests for the capacity of a single MHC class I allele to protect from disease require the isolation of suitable recombinant haplotypes or bioengineered transfer of BF2 alleles. For example, a shift in MD resistance with transfer of the $\mathrm{BF} 2 * 2101$ (and, if necessary, the coordinate TAP alleles) into a genetically susceptible background, such as the $B 13$ haplotype, would be expected if resistance to MD is fully based in class I presentation. Other experiments might include tests to confirm the importance of $B F 2 * 1301$ in resistance to diseases caused by pathogens containing proteins with the $\mathrm{BF} 2 * 1301$ binding motif. Challenge trials of $B 13$ birds vaccinated with appropriate candidate viral peptides found experimentally to bind to BF2*1301 would be another means of investigating the contribution of this unusual allele.

\section{Acknowledgments}

The authors wish to thank Susan Kovats for guidance in peptide isolation. This project was supported in part by a City of Hope Cancer Center Seed Grant and by National Research Initiative Grants nos. 2004-35205-14203 and 2006-3505-16678 from the USDA Cooperative State Research, Education, and Extension Service.

\section{References}

Bacon LD, Witter RL. Influence of turkey herpesvirus vaccination on the B-haplotype effect on Marek's disease resistance in 15.B-congenic chickens. Avian Dis. 1992; 36:378-385. [PubMed: 1320867]

Bacon LD, Witter RL. Influence of B-haplotype on the relative efficacy of Marek's disease vaccines of different serotypes. Avian Dis. 1993; 37:53-59. [PubMed: 8383961]

Bacon LD, Witter RL. B haplotype influence on the relative efficacy of Marek's disease vaccines in commercial chickens. Poult Sci. 1994a; 73:481-487. [PubMed: 8202426]

Bacon LD, Witter RL. Serotype specificity of B-haplotype influence on the relative efficacy of Marek's disease vaccines. Avian Dis. 1994b; 38:65-71. [PubMed: 8002902]

Bacon LD, Witter RL. Efficacy of Marek's disease vaccines in Mhc heterozygous chickens: Mhc congenic $\times$ inbred line F1 matings. J Hered. 1995; 86:269-273. [PubMed: 7657994]

Bacon LD, Hunt HD, Cheng HH. Genetic resistance to Marek's disease. Curr Top Microbiol Immunol. 2001; 255:121-141. [PubMed: 11217420]

Briles WE, Briles RW, Taffs RE, Stone HA. Resistance to a malignant lymphoma in chickens is mapped to subregion of major histocompatibility (B) complex. Science. 1983; 219:977-979. [PubMed: 6823560]

Briles WE, Stone HA, Cole RK. Marek's disease: effects of B histocompatibility alloalleles in resistant and susceptible chicken lines. Science. 1977; 195:193-195. [PubMed: 831269]

Collins EJ, Garboczi DN, Wiley DC. Three-dimensional structure of a peptide extending from one end of a class I MHC binding site. Nature. 1994; 371:626-629. [PubMed: 7935798]

Cox AL, Skipper J, Chen Y, Henderson RA, Darrow TL, Shabanowitz J, Engelhard VH, Hunt DF, Slingluff CL Jr. Identification of a peptide recognized by five melanoma-specific human cytotoxic T cell lines. Science. 1994; 264:716-719. [PubMed: 7513441]

Cumberbatch JA, Brewer D, Vidavsky I, Sharif S. Chicken major histocompatibility complex class II molecules of the B haplotype present self and foreign peptides. Anim Genet. 2006; 37:393-396. [PubMed: 16879355] 
Deverson EV, Leong L, Seelig A, Coadwell WJ, Tredgett EM, Butcher GW, Howard JC. Functional analysis by site-directed mutagenesis of the complex polymorphism in rat transporter associated with antigen processing. J Immunol. 1998; 160:2767-2779. [PubMed: 9510178]

Falk K, Rotzschke O, Stevanovic S, Jung G, Rammensee HG. Allele-specific motifs revealed by sequencing of self-peptides eluted from MHC molecules. Nature. 1991; 351:290-296. [PubMed: 1709722]

Fremont DH, Matsumura M, Stura EA, Peterson PA, Wilson IA. Crystal structures of two viral peptides in complex with murine MHC class I H-2Kb. Science. 1992; 257:919-927. [PubMed: 1323877]

Fulton JE, Thacker EL, Bacon LD, Hunt HD. Functional analysis of avian class I (BFIV) glycoproteins by epitope tagging and mutagenesis in vitro. Eur J Immunol. 1995; 25:2069-2076. [PubMed: 7621880]

Guillemot F, Billault A, Pourquie O, Behar G, Chausse AM, Zoorob R, Kreibich G, Auffray C. A molecular map of the chicken major histocompatibility complex: the class II beta genes are closely linked to the class I genes and the nucleolar organizer. EMBO J. 1988; 7:2775-2785. [PubMed: 3141149]

Guo HC, Jardetzky TS, Garrett TP, Lane WS, Strominger JL, Wiley DC. Different length peptides bind to HLA-Aw68 similarly at their ends but bulge out in the middle. Nature. 1992; 360:364-366. [PubMed: 1448153]

Haeri M, Read LR, Wilkie BN, Sharif S. Identification of peptides associated with chicken major histocompatibility complex class II molecules of B21 and B19 haplotypes. Immunogenetics. 2005; 56:854-859. [PubMed: 15650875]

Ho SN, Hunt HD, Horton RM, Pullen JK, Pease LR. Site-directed mutagenesis by overlap extension using the polymerase chain reaction. Gene. 1989; 77:51-59. [PubMed: 2744487]

Hunt HD, Fulton JE. Analysis of polymorphisms in the major expressed class I locus (B-FIV) of the chicken. Immunogenetics. 1998; 47:456-467. [PubMed: 9553152]

Hunt DF, Henderson RA, Shabanowitz J, Sakaguchi K, Michel H, Sevillir N, Cox AL, Appella E, Engelhard VH. Characterization of peptides bound to the class I MHC molecule HLA-A2.1 by mass spectrometry. Science. 1992; 255:1261-1263. [PubMed: 1546328]

Hunt HD, Pharr GT, Bacon LD. Molecular analysis reveals MHC class I intra-locus recombination in the chicken. Immunogenetics. 1994; 40:370-375. [PubMed: 7927541]

Joly AL, Le Rolle AL, Gonzalez AL, Mehling WJ, Stevens WJ, Coadwell WJ, Hunig JC, Howard JC, Butcher GW. Coevolution of rat TAP transporters and MHC class I RT1-A molecules. Curr Biol. 1998; 8:169-172. [PubMed: 9443915]

Juul-Madsen HR, Dalgaard TS, Afanassieff M. Molecular characterization of major and minor MHC class I and II genes in B21-like haplotypes in chickens. Anim Genet. 2000; 31:252-261. [PubMed: 11086534]

Kaufman J. Co-evolving genes in MHC haplotypes: the "rule" for nonmammalian vertebrates? Immunogenetics. 1999; 50:228-236. [PubMed: 10602883]

Kaufman J, Salomonsen J. What in the dickens is with these chickens? An only slightly silly response to the first draft of Langman and Cohn. Res Immunol. 1993; 144:495-502. [PubMed: 8303071]

Kaufman J, Salomonsen J, Flajnik M. Evolutionary conservation of MHC class I and class II molecules_-different yet the same. Semin Immunol. 1994; 6:411-424. [PubMed: 7654997]

Kaufman J, Volk H, Wallny HJ. A "minimal essential Mhc" and an "unrecognized Mhc": two extremes in selection for polymorphism. Immunol Rev. 1995; 143:63-88. [PubMed: 7558083]

Kaufman J, Jacob J, Shaw I, Walker B, Milne S, Beck S, Salomonsen J. Gene organisation determines evolution of function in the chicken MHC. Immunol Rev. 1999a; 167:101-117. [PubMed: 10319254]

Kaufman J, Milne S, Gobel TW, Walker BA, Jacob JP, Auffray C, Zoorob R, Beck S. The chicken B locus is a minimal essential major histocompatibility complex. Nature. 1999b; 401:923-925. [PubMed: 10553909]

Koch M, Camp S, Collen T, Avila D, Salomonsen J, Wallny HJ, van Hateren A, Hunt L, Jacob JP, Johnston F, Marston DA, Shaw I, Dunbar PR, Cerundolo V, Jones EY, Kaufman J. Structures of 
an MHC class I molecule from B21 chickens illustrate promiscuous peptide binding. Immunity. 2007; 27:885-899. [PubMed: 18083574]

Lee LF, Bacon LD, Yoshida S, Yanagida N, Zhang HM, Witter RL. The efficacy of recombinant fowl pox vaccine protection against Marek's disease: its dependence on chicken line and B haplotype. Avian Dis. 2004; 48:129-137. [PubMed: 15077806]

Lin HH, Ray S, Tongchusak S, Reinherz EL, Brusic V. Evaluation of MHC class I peptide binding prediction servers: application for vaccine research. BMC Immunol. 2008; 9:8. [PubMed: 18366636]

Madden DR. The three-dimensional structure of peptide-MHC complexes. Annu Rev Immunol. 1995; 13:587-622. [PubMed: 7612235]

Maenaka K, Jones EY. MHC superfamily structure and the immune system. Curr Opin Struct Biol. 1999; 9:745-753. [PubMed: 10607669]

Matsumura M, Fremont DH, Peterson PA, Wilson IA. Emerging principles for the recognition of peptide antigens by MHC class I molecules. Science. 1992; 257:927-934. [PubMed: 1323878]

Okazaki W, Witter RL, Romero C, Nazerian K, Sharma JM, Fadly A, Ewert D. Induction of lymphoid leukosis transplantable tumours and the establishment of lymphoblastoid cell lines. Avian Pathology. 1980; 9:311-329. [PubMed: 18770270]

Pamer E, Cresswell P. Mechanisms of MHC class I-restricted antigen processing. Annu Rev Immunol. 1998; 16:323-358. [PubMed: 9597133]

Petropoulos CJ, Hughes SH. Replication-competent retrovirus vectors for the transfer and expression of gene cassettes in avian cells. J Virol. 1991; 65:3728-3737. [PubMed: 2041092]

Plachy J, Jurajda V, Benda V. Resistance to Marek's disease is controlled by a gene within the B-F region of the chicken major histocompatibility complex in Rous sarcoma regressor or progressor inbred lines of chickens. Folia Biol (Praha). 1984; 30:251-258. [PubMed: 6090234]

Powis SJ, Young LL, Joly E, Barker PJ, Richardson L, Brandt RP, Melief CJ, Howard JC, Butcher GW. The rat cim effect: TAP allele-dependent changes in a class I MHC anchor motif and evidence against C-terminal trimming of peptides in the ER. Immunity. 1996; 4:159-165. [PubMed: 8624806]

Rotzschke O, Falk K, Stevanovic S, Jung G, Rammensee HG. Peptide motifs of closely related HLA class I molecules encompass substantial differences. Eur J Immunol. 1992; 22:2453-2456. [PubMed: 1516632]

Rudolph MG, Stanfield RL, Wilson IA. How TCRs bind MHCs, peptides, and coreceptors. Annu Rev Immunol. 2006; 24:419-466. [PubMed: 16551255]

Sali A, Blundell TL. Comparative protein modelling by satisfaction of spatial restraints. J Mol Biol. 1993; 234:779-815. [PubMed: 8254673]

Shiina T, Briles WE, Goto RM, Hosomichi K, Yanagiya K, Shimizu S, Inoko H, Miller MM. Extended gene map reveals tripartite motif, C-type lectin, and Ig superfamily type genes within a subregion of the chicken MHC-B affecting infectious disease. J Immunol. 2007; 178:7162-7172. [PubMed: 17513765]

Speir JA, Stevens J, Joly E, Butcher GW, Wilson IA. Two different, highly exposed, bulged structures for an unusually long peptide bound to rat MHC class I RT1-Aa. Immunity. 2001; 14:81-92. [PubMed: 11163232]

Sudo T, Kamikawaji N, Kimura A, Date Y, Savoie CJ, Nakashima H, Furuichi E, Kuhara S, Sasazuki T. Differences in MHC class I self peptide repertoires among HLA-A2 subtypes. J Immunol. 1995; 155:4749-4756. [PubMed: 7594476]

Thacker EL, Fulton JE, Hunt HD. In vitro analysis of a primary, major histocompatibility complex (MHC)-restricted, cytotoxic T-lymphocyte response to avian leukosis virus (ALV), using target cells expressing MHC class I cDNA inserted into a recombinant ALV vector. J Virol. 1995; 69:6439-6444. [PubMed: 7666545]

Tong JC, Tan TW, Ranganathan S. Modeling the structure of bound peptide ligands to major histocompatibility complex. Protein Sci. 2004; 13:2523-2532. [PubMed: 15322290]

Tynan FE, Borg NA, Miles JJ, Beddoe T, El-Hassen D, Silins SL, van Zuylen WJ, Purcell AW, KjerNielsen L, McCluskey J, Burrows SR, Rossjohn J. High resolution structures of highly bulged viral epitopes bound to major histocompatibility complex class I. Implications for T-cell receptor 
engagement and T-cell immunodominance. J Biol Chem. 2005; 280:23900-23909. [PubMed: 15849183]

Walker BA, van Hateren A, Milne S, Beck S, Kaufman J. Chicken TAP genes differ from their human orthologues in locus organisation, size, sequence features and polymorphism. Immu-nogenetics. 2005; 57:232-247.

Wallny HJ, Avila D, Hunt LG, Powell TJ, Riegert P, Salomonsen J, Skjodt K, Vainio O, Vilbois F, Wiles MV, Kaufman J. Peptide motifs of the single dominantly expressed class I molecule explain the striking MHC-determined response to Rous sarcoma virus in chickens. Proc Natl Acad Sci U S A. 2006; 103:1434-1439. [PubMed: 16432226]

Wong GK, Liu B, Wang J, Zhang Y, Yang X, Zhang Z, Meng Q, Zhou J, Li D, Zhang J, Ni P, Li S, Ran L, Li H, Zhang J, Li R, Li S, Zheng H, Lin W, Li G, Wang X, Zhao W, Li J, Ye C, Dai M, Ruan J, Zhou Y, Li Y, He X, Zhang Y, Wang J, Huang X, Tong W, Chen J, Ye J, Chen C, Wei N, Li G, Dong L, Lan F, Sun Y, Zhang Z, Yang Z, Yu Y, Huang Y, He D, Xi Y, Wei D, Qi Q, Li W, Shi J, Wang M, Xie F, Wang J, Zhang X, Wang P, Zhao Y, Li N, Yang N, Dong W, Hu S, Zeng C, Zheng W, Hao B, Hillier LW, Yang SP, Warren WC, Wilson RK, Brandstrom M, Ellegren H, Crooijmans RP, van der Poel JJ, Bovenhuis H, Groenen MA, Ovcharenko I, Gordon L, Stubbs L, Lucas S, Glavina T, Aerts A, Kaiser P, Rothwell L, Young JR, Rogers S, Walker BA, van Hateren A, Kaufman J, Bumstead N, Lamont SJ, Zhou H, Hocking PM, Morrice D, de Koning DJ, Law A, Bartley N, Burt DW, Hunt H, Cheng HH, Gunnarsson U, Wahlberg P, et al. A genetic variation map for chicken with 2.8 million single-nucleotide polymorphisms. Nature. 2004; 432:717-722. [PubMed: 15592405] 


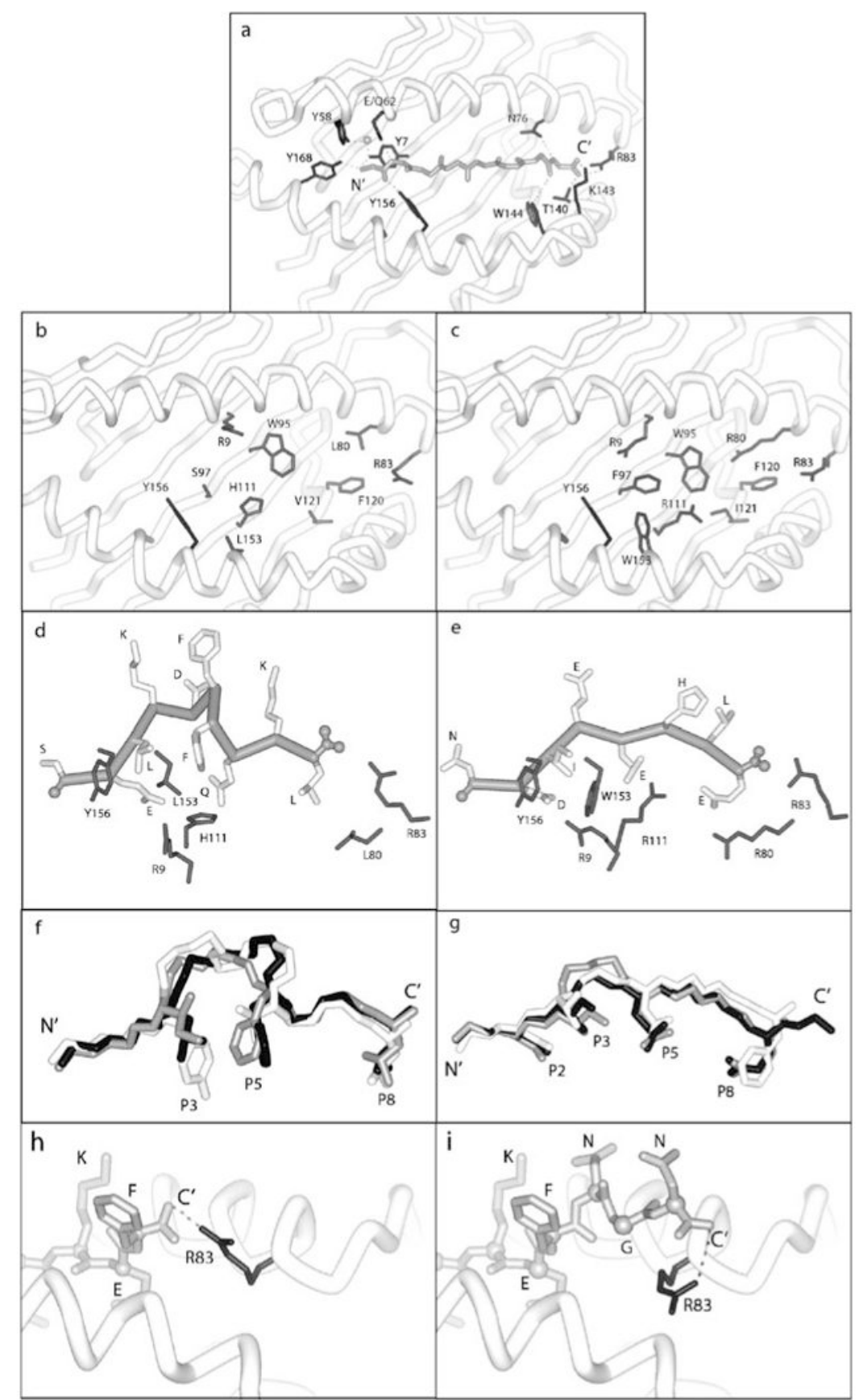

Fig. 1.

Molecular modeling of peptides bound to $\mathrm{BF} 2 * 2101$ and $\mathrm{BF} 2 * 1301$. The views are from above in a-c and from the side in $\mathbf{d - i}$. a Modeling of peptides bound within BF2*2101 and $\mathrm{BF} 2 * 1301$ binding grooves indicates that tyrosine residues (Y7, Y58, Y156, and Y168) and E/Q62 participate in main chain interactions with the amino-terminus of peptide while the peptide carboxy-terminus is bound by similar interactions with N76, R83, T140, K143, and W144 as illustrated here with an octameric peptide. b Residues that interact with anchor positions in $\mathrm{BF} 2 * 2101$ peptides are labeled. $\mathbf{c}$ Residues that interact with anchor positions in BF2*1301 peptides are labeled. $\mathbf{d}$ The key binding site residues (R9, L153, H111, and L80) 
in $\mathrm{BF} 2 * 2101$ are shown relative to anchor residues along with the $\mathrm{Y} 156$ and $\mathrm{R} 83$ residues that contact the amino- and carboxy-termini of the peptide decamer SELKDFFQKL. e The three arginine residues (R9, R111, and R80) that are critical for binding the negatively charged anchor residues found in BF2*1301 peptides, the aromatic residues (W153 and also Y156) that bind the hydrophobic position 3 anchor, and the contacts for amino-terminus (Y156) and carboxy-terminus (R83) of the peptide are shown relative to the peptide octamer NDIEEHLE. f Representative nona-, deca-, and dodeca-peptides (peptides 3, 9, and 32 in Fig. 2) bound to BF2*2101. The side chains of the three anchor residues are shown. Position 3 residue is typically hydrophobic and, unlike in $\mathrm{BF} 2 * 1301$, it can vary greatly in size. It interacts primarily with Y156 and L153. The next anchor residue position 5, also typically hydrophobic, interacts with H111, F123, L153, W144, and Y149. The last anchor, position 8 , is always hydrophobic because of the presence of L80 which together with W95, F120, and V121 create a completely hydrophobic pocket. Longer peptides arch out of the groove in order to accommodate anchor residue binding. $\mathrm{g}$ Representative octa- and nona-peptides (peptides 2, 8, and 11 in Fig. 3) are shown bound to BF2*1301. The side chains of the four anchor residues are shown. In all three peptides shown, position 2 is negatively charged and interacts with R9. The position 3 residues are hydrophobic and interact with W153, F97, and Y156. Position 8 residues, when negatively charged, interact with R80. When hydrophobic or neutral (peptide 2, shown in white), position 8 interacts primarily with the aliphatic stalk of R80. Nonameric peptide 8 kinks to fit within the groove so that the middle negatively charged residue (see Fig. 3) moves to position 5 and interacts with R111. Nonameric peptide 11 is modeled without a kink. Instead R83 moves to accommodate the extra residue. $\mathbf{h}$ Among the peptides eluted from $\mathrm{BF} 2 * 1301$ are two sharing overlapping sequence. The sequence of the nonameric peptide 30 is found within the sequence of dodecameric peptide 29 (see Fig. 3). These are modeled with C-terminal residues extending out along the groove axis so that the highly conserved negatively charged anchor residue at position 8 remains in its binding pocket. The C-terminal interaction of peptide 30 is illustrated showing R83 pointing inward and forming a salt bridge with the carboxy-terminus of the nonameric peptide 30. i Because it is so flexible, R83 is able to accommodate the dodecameric peptide 29 by pointing away from the groove while still forming a salt bridge with the carboxyterminus 


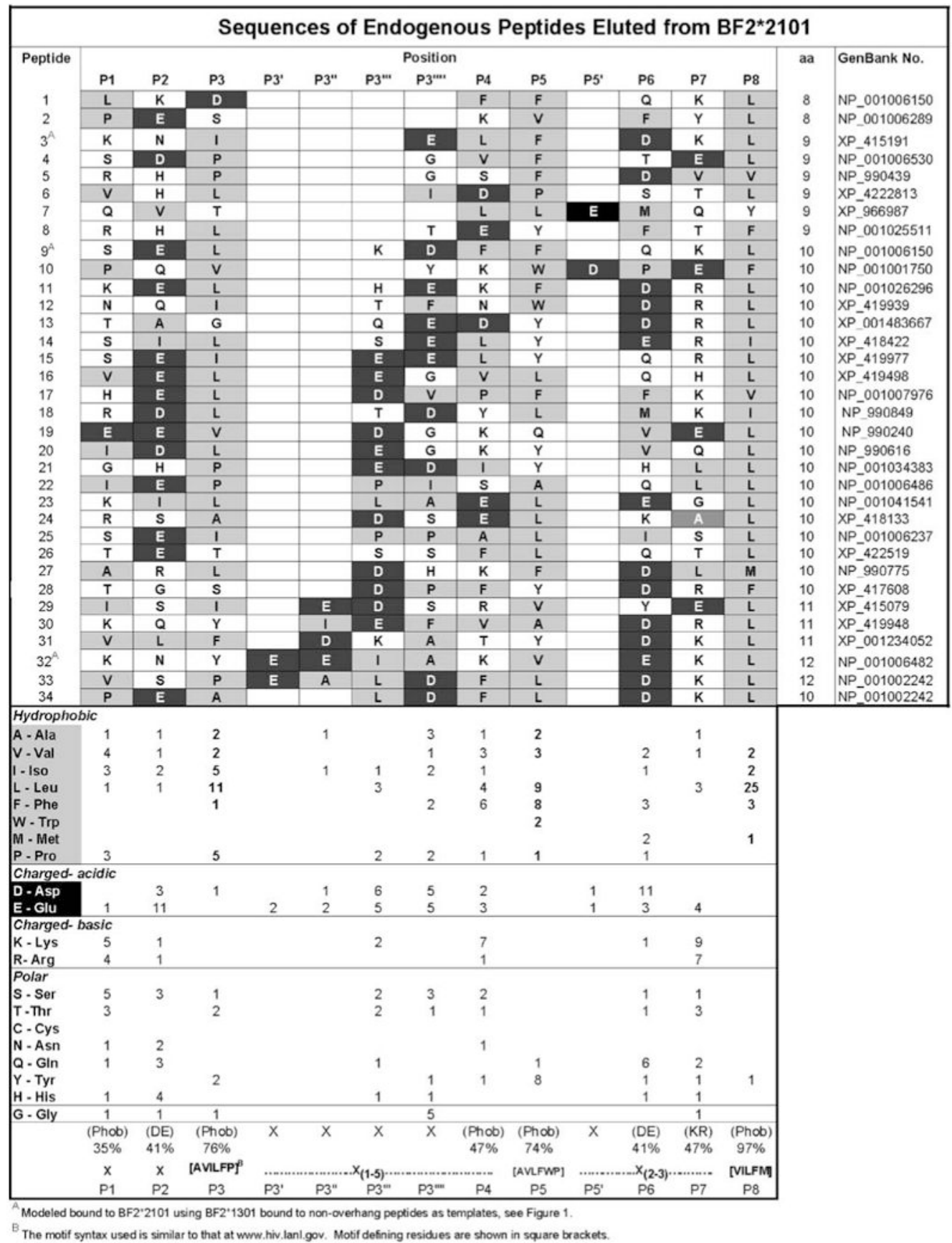

Fig. 2.

The sequence for 34 endogenous peptides eluted from the BF2*2101 allele are aligned to reveal the $\mathrm{BF} 2 * 2101$ peptide binding motif. Molecular modeling of peptide-BF2*2101 complex suggests that the ends of all $34 \mathrm{BF} 2 * 2101$ peptides are bound at the margins of the antigen binding groove and that longer peptides bulge as a result (see Fig. 1f). To bring the $\mathrm{N}$ - and C-termini of all peptides into line, gap positions $\left(3^{\prime}, 3^{\prime \prime}, 3^{\prime \prime \prime}, 3^{\prime \prime \prime \prime}\right.$, and $\left.5^{\prime}\right)$ were introduced into the alignment in the regions corresponding to bulges. The alignment reveals the patterns of anchor residues shared by the 34 peptides. All 34 peptides have a C-terminal hydrophobic (Phob) residue (most often L, but also V, I, F, M, or Y, the latter residue has hydrophobic properties) at position 8 . The prevalence of hydrophobic residues at position 3 
(26/34 are A, V, I, L, F, P) and position 5 (31/34 are A, V, L, F, W, P) suggests that additional hydrophobic interactions along the binding groove guide peptide selection. In addition, glutamic and aspartic acid residues are preferred at positions 2 and 6 . The peptides are as follows: NP_001006289, Y-3-monooxygenase-W-5-monooxygenase activation, beta; NP_001006150, ras GTPase-activating protein SH2-domain binding protein; XP_415191, similar to MSPT028; NP_001006530, ubiquitin carboxyl-terminal hydrolase L5; NP_990439, ribosomal protein S4; XP_4222813, hypothetical protein; XP_966987, predicted: similar to CG8465-PA, isoform A; NP_001025511, protein phosphatase 3, catalytic subunit, beta isoform; NP_001026296, septin 6; XP_419939, predicted: similar to KIAA1250; XP_001483667, similar to cell division control protein 42; XP_418422, similar to KIAA1882 protein;XP_41997, predicted: similar to HCLS1 binding protein 3; XP_419498, predicted: hypothetical protein; NP_001007976, $N$-acetylneuraminic acid synthase; NP_990849, beta actin; NP_990240, ras homolog gene family, member B; NP_990616, lamin B2; NP_001034383, farnesyl-diphosphate farnesyl transferase; NP_001006486, SET domain containing 3 (bursal protein); NP_001041541, vimentin; XP_418133, hypothetical similar to RUN domain containing 1 isoform 1; NP_001006237, RAN ATPase-activating protein 1; XP_422519, dedicator of cytokinesis 7; NP_990775, tubulin, alpha 8; XP_417608, similar to kinesin family member 1B; NP_001001750, beta-2 microglobulin; XP_415079, DiGeorge Syndrome critical gene; XP_419948, similar to small subunit ribonucleotide reductase isoform 2; XP_001234052, predicted: similar to ribosomal protein S25 reductase; NP_001006482, transmembrane emp 24 domain containing protein; and NP_001002242, casein kinase II 


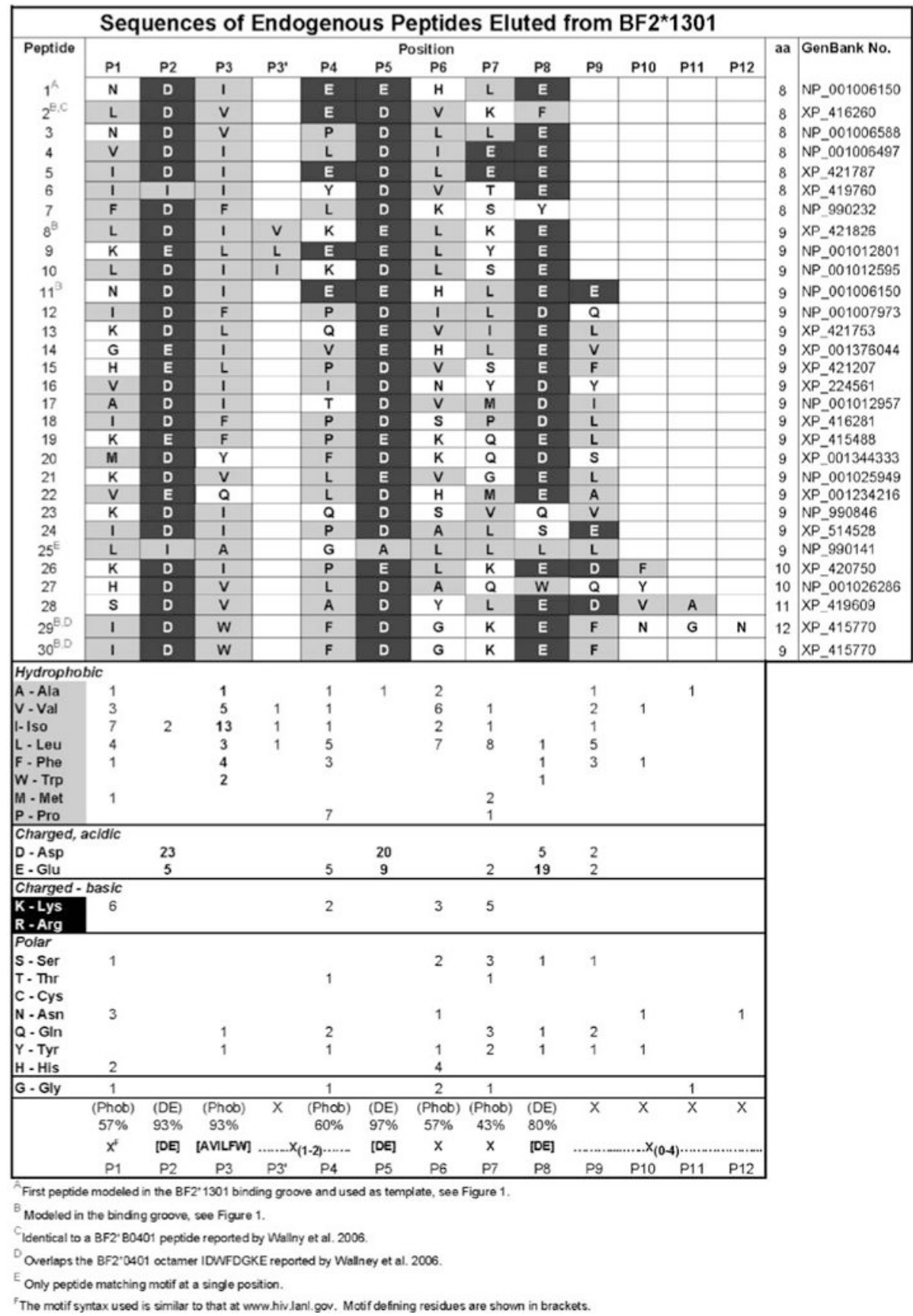

Fig. 3.

Alignment of 30 endogenous peptides eluted from the $\mathrm{BF} 2 * 1301$ allele and the derived motif. The alignment, assisted by molecular modeling of peptide-BF $2 * 1301$ complex, reveals the importance of acidic (D-E) and hydrophobic residues (Phob) in the selection of $\mathrm{BF} 2 * 1301$ peptides. Aspartic and glutamic acids were found nearly exclusively at three positions (P2, P5, and P8) with peptides also selected for hydrophobic residues present especially at position 3 , thus defining four anchor residues for the BF2*1301 allele. More than half the peptides also have hydrophobic residues at positions 1, 4, and 6 even though these are not predicted anchor residues. Structural modeling suggests that longer peptides interact in the BF2*1301 binding groove in two different ways. Some peptides, represented 
by nonameric peptides 8,9 , and 10 , are likely accommodated as a result of bulging from the groove. Other nonameric peptides (peptides 11-25 and 30) and even longer peptides with up to 12 residues (peptides 26-29) may extend out along the groove axis as a result of the flexibility of Arg83. The peptides originate from: NP_001006497, DNA replication helicase-2-like+R50; XP_421787, predicted: similar to p167; NP_001006588, hypoxia upregulated 1; XP_419760, predicted: similar to heat shock factor protein 2; NP_990232, eukaryotic translation elongation factor 1 beta 2; XP_416260, predicted: similar to DEAD box polypeptide; NP_001006150, Ras GTPase-activating protein SH3-domain binding protein; NP_001006150, Ras GTPase-activating protein SH3-domain binding protein; NP_001007973, predicted: hypothetical protein; XP_421753, predicted: 30-kDa splicing factor; XP_001376044, cell division cycle protein 23; XP_421207, predicted: hypothetical protein; XP_224561, predicted: similar to Filamin-B (FLN-B; Beta-filamin); NP_001012957, hypothetical protein LOC426469; XP_416281, predicted: similar to PVA354; XP_415488, predicted: similar to Zyg-11 homolog B (C. elegans)-like in $G$. gallus; XP_001344333, predicted: similar to serine-threonine kinase 3; NP_001025949, Mak3 homolog; XP_001234216, predicted: similar to GINS complex subunit 4 (Sld5 homolog); NP_990846, capping protein (actin filament) muscle Z-line alpha 1; XP_514528, predicted: sorting nexin 5 [Pan troglodytes]; NP_001012801, kinesin family member 20A; NP_001012595, hypothetical protein LOC422534; XP_421826, predicted: similar to thioredoxin like; NP_990141, leukocyte cell-derived chemotaxin 1; XP_420750, predicted: similar to TBC1 domain family member 19; NP_001026286, dyskeratosis congenita 1, dyskerin; XP_419609, predicted: FGFR1 oncogene partner; XP_415770, predicted:

hypothetical protein; and XP_415770, predicted: hypothetical protein 
Table 1

Peptide binding motif matches within the 85 proteins $(44,320$ amino acids) of Gallid herpesvirus 2, GenBank NC_002229, and within the oncoprotein Meq

\begin{tabular}{|c|c|c|c|}
\hline Allele & Peptide binding motif & Overall & Meq \\
\hline \multicolumn{4}{|c|}{ Matches in a comparison of $\mathrm{BF} 2 * 2101$ and $\mathrm{BF} 2 * 1301$ peptide binding motifs } \\
\hline $\mathrm{BF} 2 * 2101$ & $\mathrm{XX}[\mathrm{AVILFP}] \mathrm{X}_{(1-5)}[\mathrm{AVLFWP}] \mathrm{X}_{(2-3)}[\mathrm{VILFM}]$ & 15,652 & 119 \\
\hline $\mathrm{BF} 2 * 1301$ & $\mathrm{X}[\mathrm{DE}][\mathrm{AVILFW}] \mathrm{X}_{(1-2)}[\mathrm{DE}] \mathrm{XX}[\mathrm{DE}] \mathrm{X}_{(0-4)}$ & 42 & 0 \\
\hline \multicolumn{4}{|c|}{ Matches found with HLA A*0201 peptide binding motif } \\
\hline HLA A*0201 & $\mathrm{X}[\mathrm{AVILMP}] \mathrm{X}_{(6-12)}[\mathrm{AVILFMP}]$ & 46,804 & 465 \\
\hline
\end{tabular}



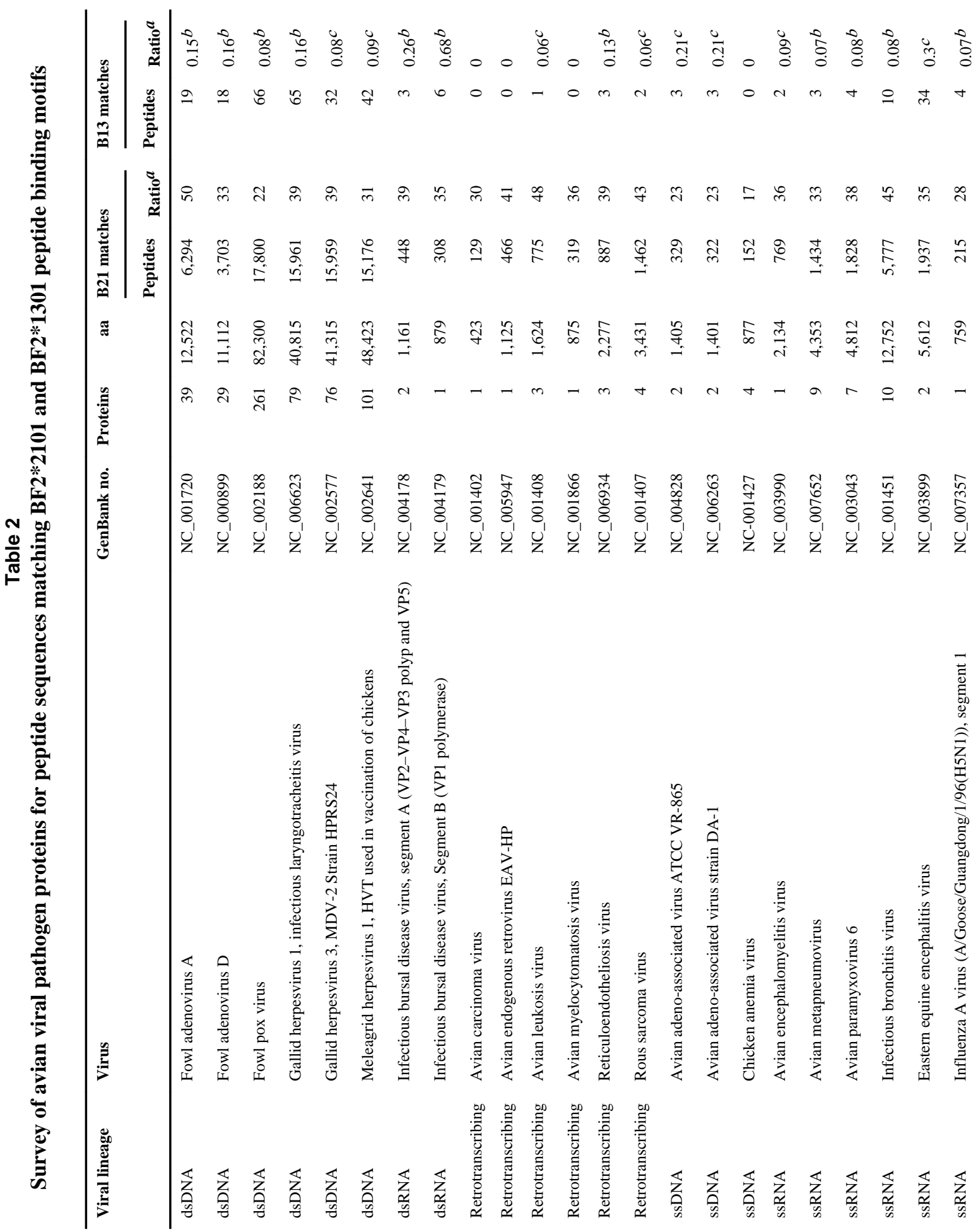


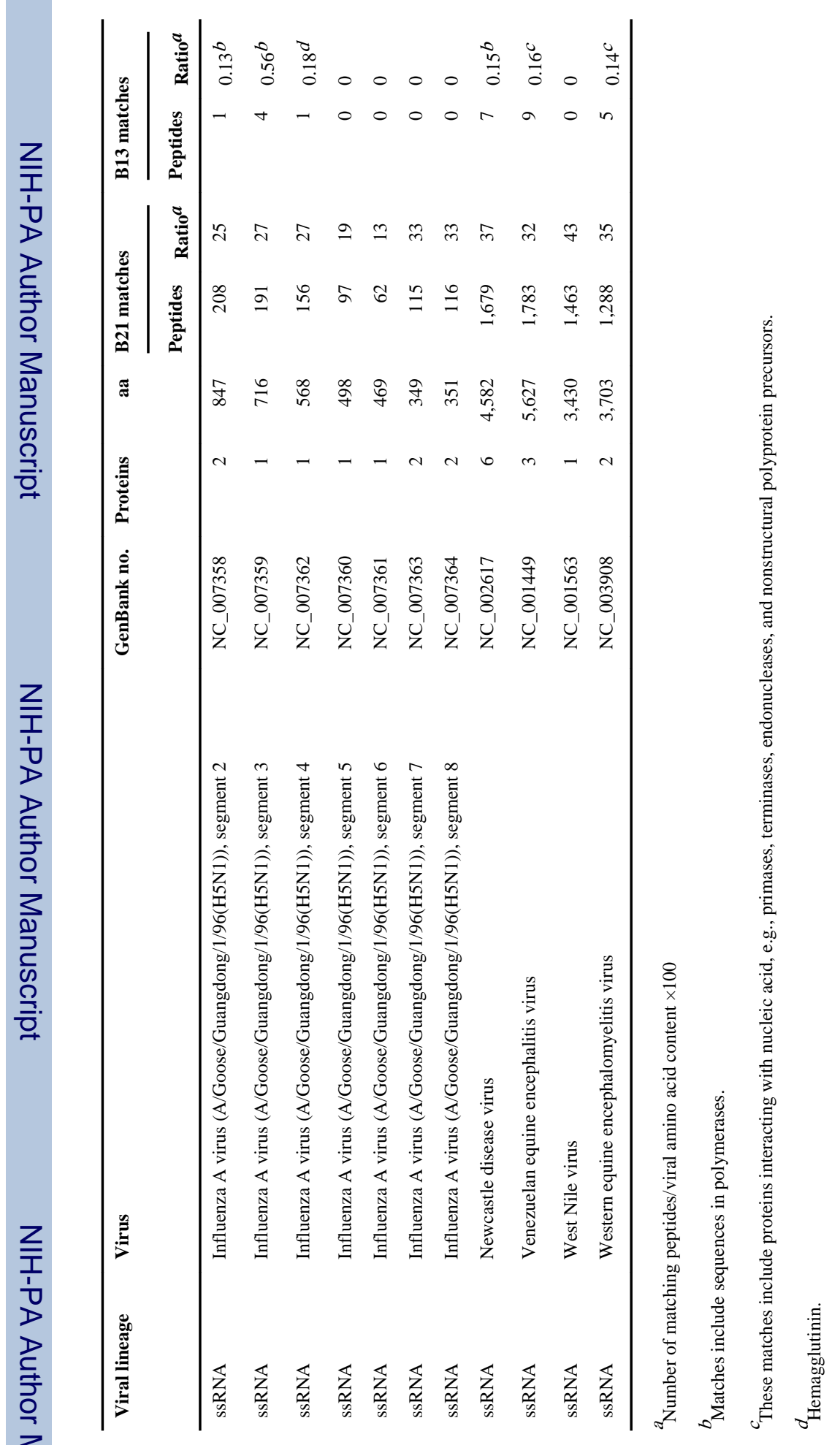

힐 


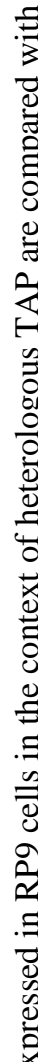

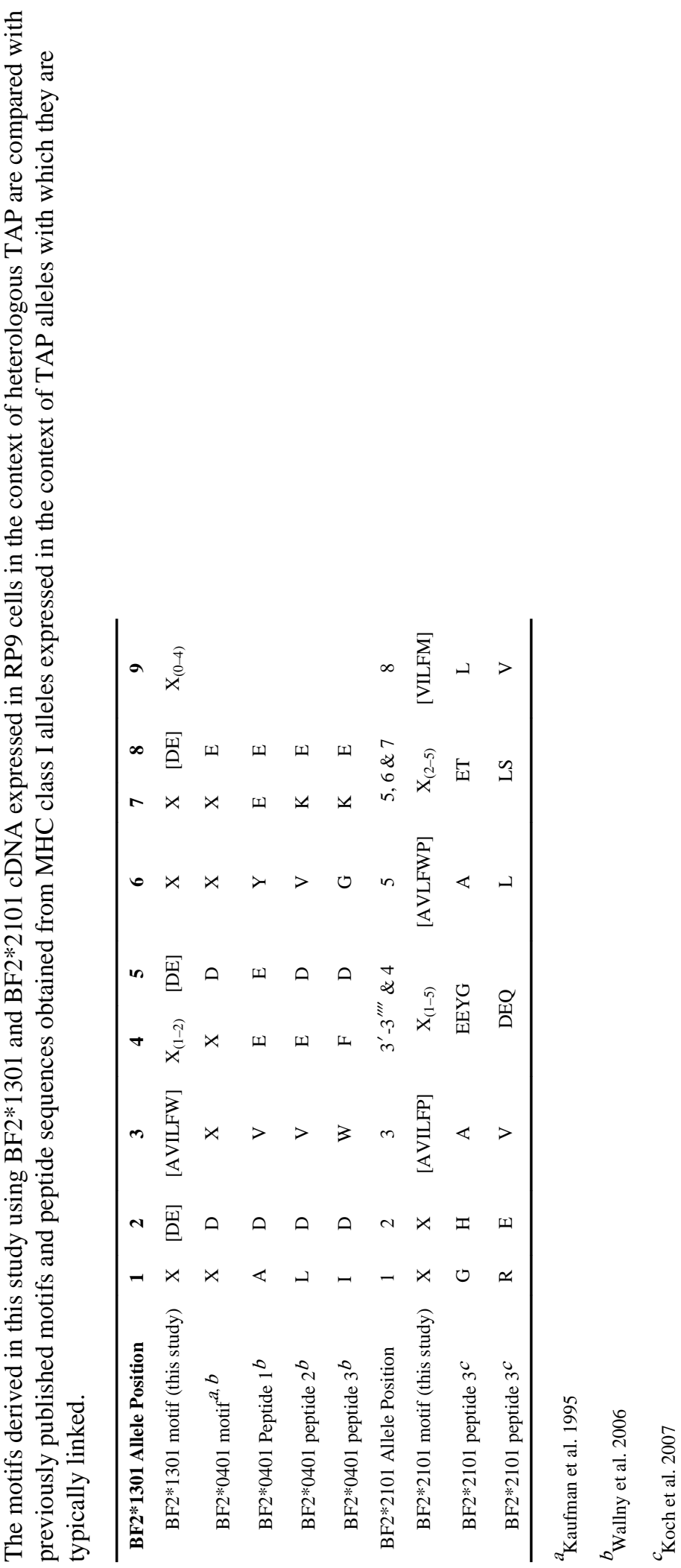

